\title{
Short communications on evaporation
}

\section{MEASURING SOIL WATER CONTENT AND EVAPORA. TION BY THE NEUTRON SCATTERING METHOD}

\author{
J. W. HOLMES
}

C.S.I.R.O. Division of Soils, (Waite Institute) Adelaide, South Australia

\section{SUMMARY}

The evaporation from the soil at a site near Adelaide was estimated from measurements of soil water content and rainfall for the period September to January, 1954-55. The neutron scattering method of obtaining soil water content values in the field was used with fair success. The size of the sample volume, scanned by the neutrons, limits its use at shallow depths, though the diameter of the probe also influences the sample volume. The calibration curve used for converting field measurements of counting rate to water content values was one obtained in principle from neutron transport theory.

Since a number of accounts have been written of the use of neutron scattering for measuring soil water content, it is sufficient, in introducing this communication, to make reference to these, where a description of the principle and general experimental features of the method may be found. BELCHER and co-workers (1950) and SpINKs and co-workers (1951) demonstrated that the idea was likely to prove a successful one in practice. GardNER and KIRKHaM (1952), Sharpe (1953), van Bavel and co-workers (1954), Gú́ron (1954) and KNIGHT and WriGHT (1954) have all elaborated the technique and interpretation of the method. Its usefulness depends largely upon a reproducible and stable calibration, which may be expressed in terms of counting rate vs. water content of the soil. So far efforts have been confined to measuring counting rate, when the source has been placed in soils of known water content.

It is possible however, with some simplifying assumptions, to calculate a calibration curve using the "Fermi age" treatment of the slowing down of fast neutrons. This will be described in Austr. Journ. of Physics. The disposition of neutron source to soil, most likely to be used, is to have the source held on a probe, which will be inserted in an auger hole in the soil, in order to satisfy, as nearly as possible, the geometry of a point source in an infinite moderating medium. In this case, it can be shown that the counting rate $\mathbf{n}^{\prime}$, as measured by a $\mathrm{BF}_{3}$ counting tube, in soil of water content $\mathrm{w} c \mathrm{cc} / \mathrm{cc}$, is given by,

$$
n^{\prime}=w . F . n
$$

when $n$ is the counting rate measured in water and $F$ is the fraction

$$
F=\frac{\mathrm{e}^{-\frac{r}{L} \cdot w}\left\{1-\operatorname{ert}\left(\frac{\sqrt{\vartheta_{0}}}{L}-\frac{r}{2 \sqrt{\vartheta_{0}}} \cdot w\right)\right\}+\mathrm{e}^{\frac{r}{L} \cdot w}\left\{1-\operatorname{erf}\left(\frac{\sqrt{\vartheta_{0}}}{L}+\frac{r}{2 \sqrt{\vartheta_{0}}} \cdot w\right)\right\}}{\mathrm{e}^{-\frac{r}{L}}\left\{1-\operatorname{ert}\left(\frac{\sqrt{\vartheta_{0}}}{L}-\frac{r}{2 \sqrt{\vartheta_{0}}}\right)\right\}+\mathrm{e}^{\dot{L}}\left\{1-\operatorname{erf}\left(\frac{\sqrt{\vartheta_{0}}}{L}+\frac{r}{2 \sqrt{\vartheta_{0}}}\right)\right\}}
$$

The symbols in (2) are defined in a paper by WALLACE (1949) but it should 


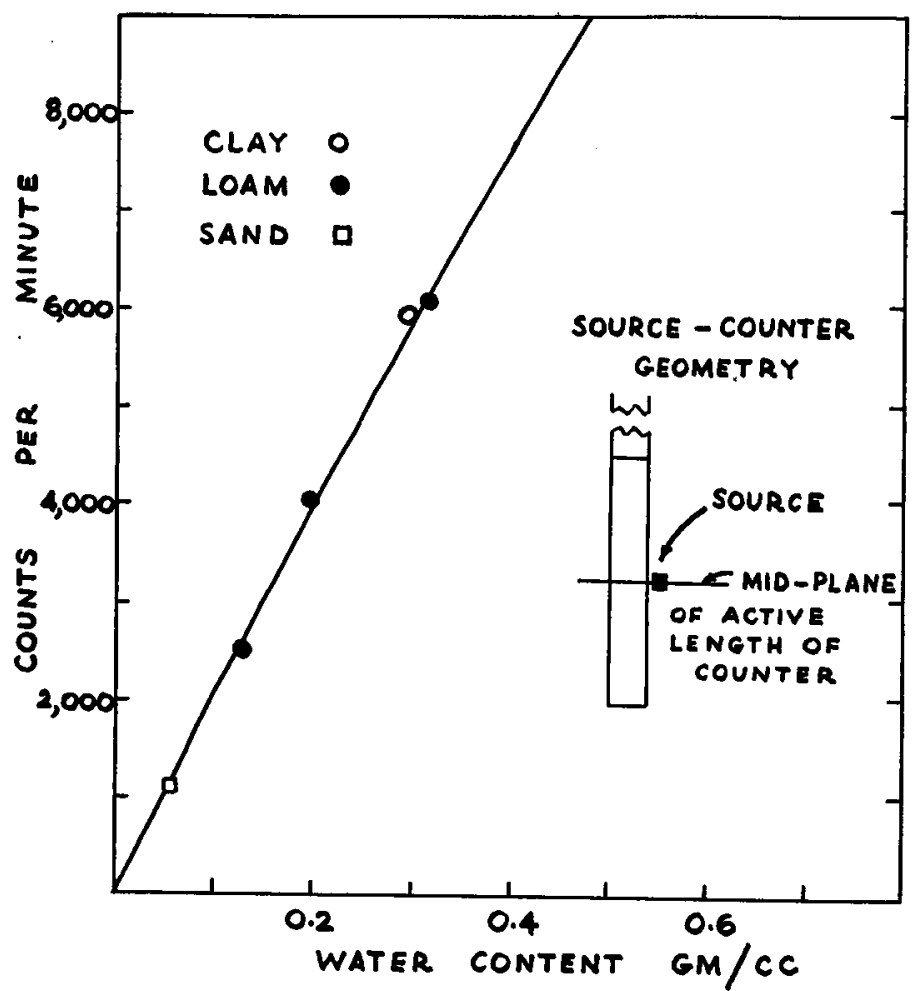

Fig. 1. Calibration curve of counting rate vs. Soll water content : With an inset of SOURCE TO COUNTER GEOMETRY.

be stated explicitly, here, that $F$ is the mean distance from the source of fast neutrons to the sensitive volume of the counting tube.

A calibration curve calculated by Eq. (1) is shown in Fig. 1 together with some experimental points, done in the field, in soils whose water contents were subsequently measured. Although the agreement is apparently good, there are reasons, which will be discussed elsewhere, for feeling dissatisfied as yet with the treatment. Fig. 1 is reproduced because that is the calibration curve which was used in converting measurements made in the field to water content profiles of soils.

These measurements took the form of trying to find out how well evaporation from the soil could be estimated by this method. The water contents of the soil at two sites, a lucerne field and a "field station" site already described (Aitchison and Holmes, 1953), were measured on a series of occasions from September to January 1954-55. At this time of the year in southern Australia the soil generally dries out steadily from its condition of maximum accumulation of water at the end of the winter. The water content profiles of Hole 2, field station site, are shown in Fig. 2. Measurements were made at vertical intervals of $30 \mathrm{~cm}$ to a depth of $180 \mathrm{~cm}$. No measurements were made closer to the surface of the soil than $30 \mathrm{~cm}$, because the size of the sample volume scanned by the neutrons does not permit it. VAN BAVEL et al. (loc. cit.) measured the size of the sample volume at a number of different 


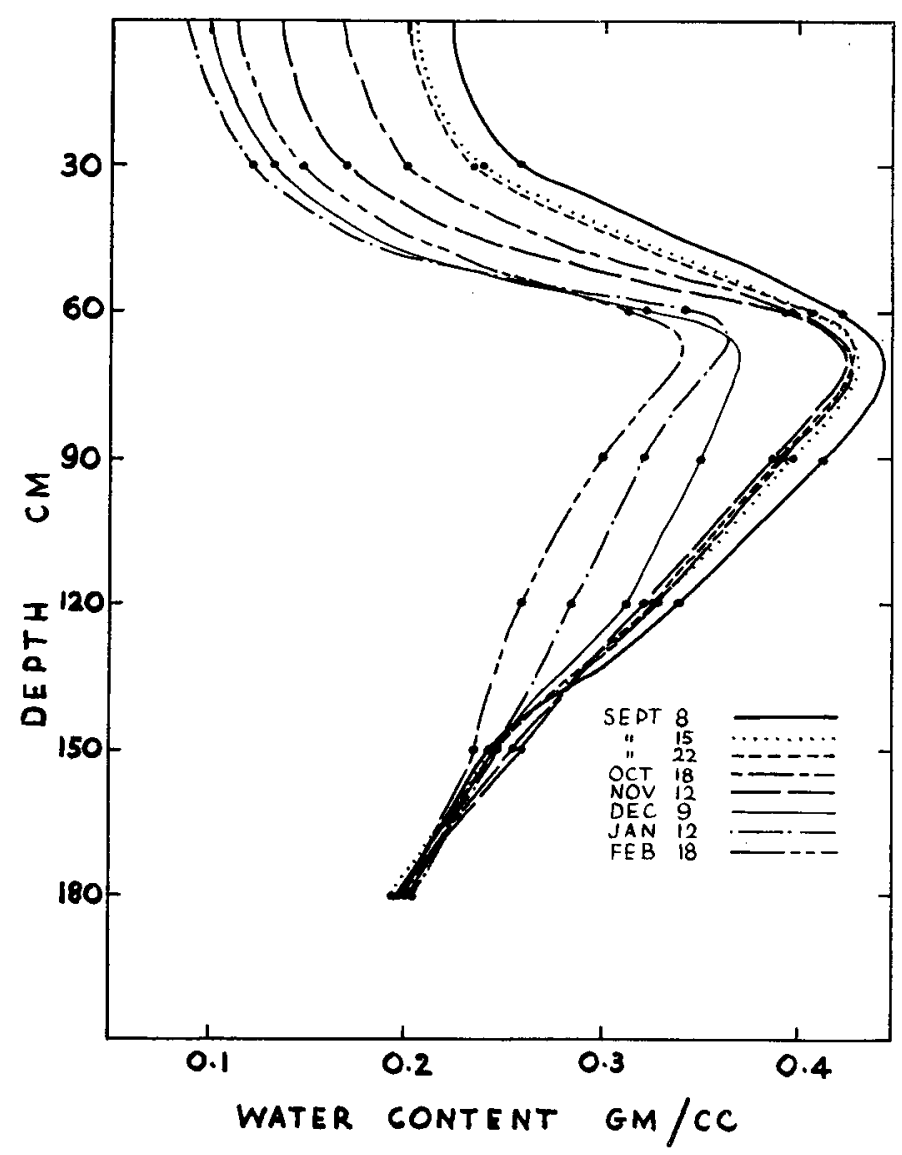

Fig. 2. Water content profiles of the soil: Hole 2, field station site.

soil water contents and our measurements, shown in Fig. 3, are in reasonable agreement with theirs. At a water content of about $0.13 \mathrm{gm} / \mathrm{cc}$ the vertical radius of the sample volume is $30 \mathrm{~cm}$. The field results at this depth may therefore be in error at lower water contents.

The sample volume in water was an ellipsoid of vertical radius $17 \mathrm{~cm}$ and horizontal radius $12 \mathrm{~cm}$. The size of the $\mathrm{BF}_{3}$ counting tube and the source to counter geometry, shown as an inset in Fig. 1, lead one to expect spherical symmetry for the measured volume populated by slow neutrons, and calculation reveals that it is the dimensions of the probe which lead to an ellipsoid for the apparent sample volume. Since the source was held near the axis of the cylindrical probe, of diameter $7.6 \mathrm{~cm}$, some fast neutrons emitted from it would escape by straight line paths contained in the cylinder from which water (or soil) is displaced.

The solid angle in a cone is

$$
2 \pi(1-\cos \beta)
$$

where $\beta$ is the angle of the apex of the cone. The fractional solid angle is therefore

$$
1_{2}^{\prime}(1-\cos \beta)
$$

and this will be the fraction of neutrons escaping by these paths, assuming 


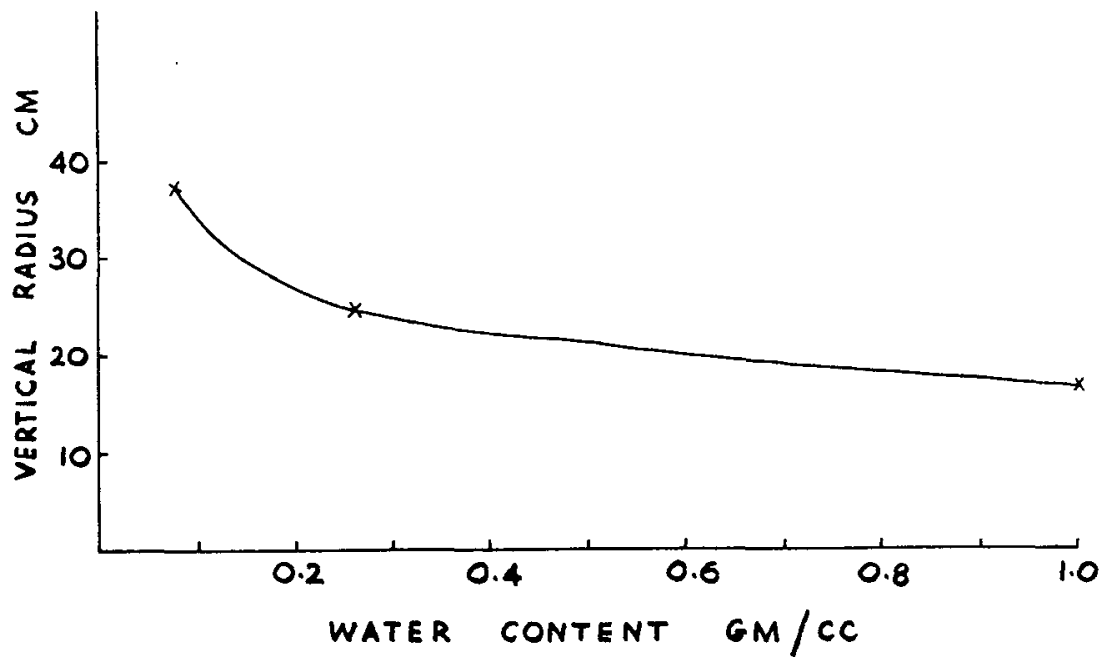

Frg. 3. Sample volume size vs, watel context.

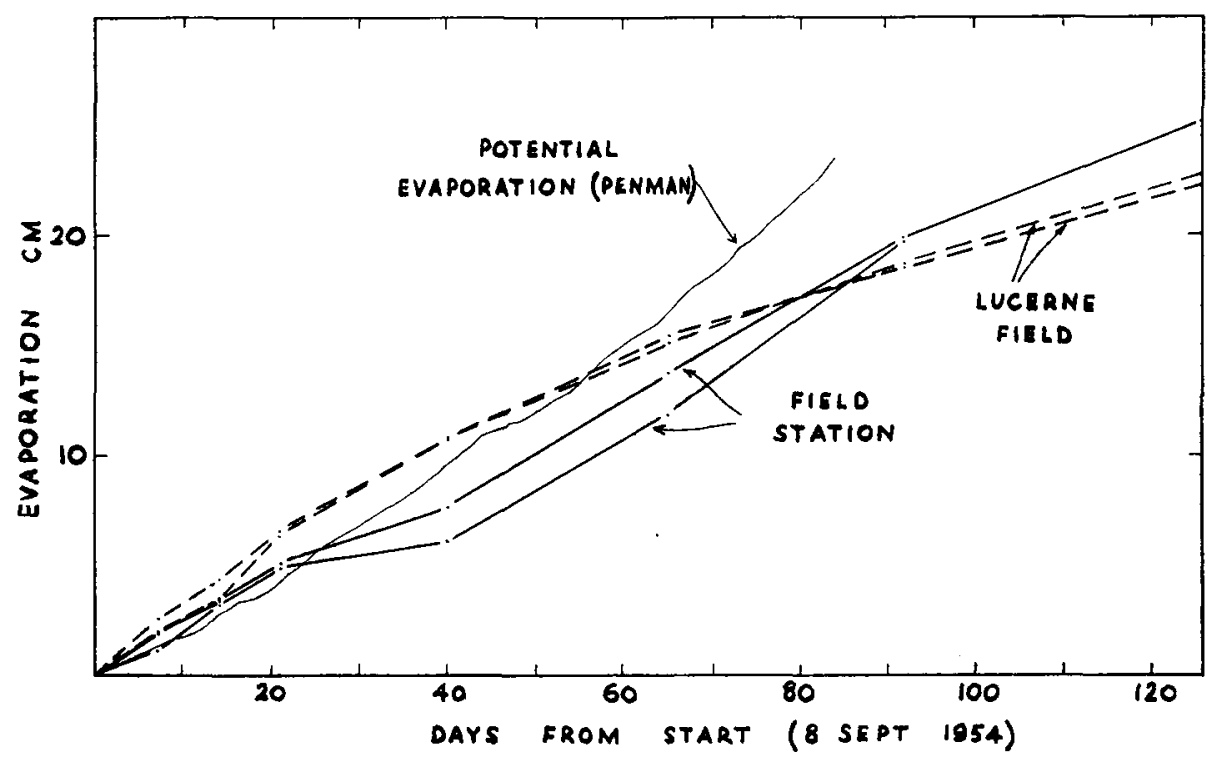

Fig. 4. Cumulative evaporation.

that none escape downwards but only in the upwards direction. When the probe is $17 \mathrm{~cm}$ below the surface, the fraction of fast neutrons escaping in this solid angle is about $1 \%$, with which compare the measured vertical radius of the sample volume in water.

The evaporation from the soil may be obtained from such curves as the ones shown in Fig. 2 by measuring the area contained between two curves, to which must be added the rainfall that has been recorded for the same period. In Fig. 4 is shown the evaporation measured by this method. For comparison the evaporation, calculated after PenMan (1952) is also shown. This and other methods for the estimation of evaporation from weather data require 
that water is available freely to the plant roots. Over the period during which the measurements of Fig. 4 were made this was certainly not the case.

I acknowledge with gratitude, the help of Mr. M. W. Hugnes in making the experimental measurements and the interest in and encouragement of this work by Dr. T. J. Marshall.

\title{
LIST OF REFERENCES
}

Aitchison, G. D. and J. W. Holsirs : Aust. J. Appl. Sci. 4 (1953) 260-273.

Baver, C. H. M. van, E. E. Hood and N. Underwood : Trans. Amer. Geophys. Union 35 (1954) 595-600.

Belcher, D. J., T. R. Cuykexdall and H. S. SACK: C.A.A., U.S.A. Tech. Development Rep. No. 127 (1950).

Gardner, W. and D. Krrkham : Soil Sci. 73 (1952) 391-401.

Gú́ron, J. : J. Phys. Radium 15 (1954) 65A-75A.

Knight, A. H. and T. W. Whight : Radioisotope Conference, Oxford (1954) Vol. II, pp. $111-122$.

Penman, H. L.: Rep. of the 13th Int. Horticultural Congress (1952) 1-12.

Sharpe, J. : Brit. J. Appl. Phys. 4 (1953) 93-94.

Spinks, J. W. T., D. A. Lane and B. B. Torchrnsky : Can. J. Technology 29 (1951) 371-374

Wallace, P. R. : Nucleonics 4 (2) (1949) 30-55.

\section{EVAPORATION AT NIGHT}

\author{
J. L. MONTEITH \\ Rothamsted Experimental Station, Harpenden, England
}

\section{SUMMARY}

Direct measurements of evaporation from a short grass surface are compared with humidity gradients in the grass. At night, when the air in the cover is unsaturated, evaporation takes place by the diffusion of water vapour from the soil surface through a thin layer of air in which the transfer coefficient is seldom greater than twice the molecular value. The rate of evaporation is of the order of $1 \mu \mathrm{g} \mathrm{cm}^{-2} \mathrm{sec}^{-1}$, or $0.04 \mathrm{~mm} / \mathrm{hr}$.

1 Little attention has been paid to evaporation from soil and from vegetation during the hours of darkness. It has generally been assumed that when weather conditions favour an upward rather than a downward movement of water vapour at night, evaporation rates are negligible compared with those which prevail during the day and this view has strong biological and physical support. It is believed that in most species stomatal closure at sunset is sufficiently complete to make transpiration impossible. Even in the absence of a mechanical barrier, no plant could transpire into an atmosphere which had been brought to saturation by nocturnal cooling. Furthermore, evaporation requires energy, and since in temperate latitudes at least the earth's surface always loses radiant energy at night, whether the sky be clear or clouded, it might be argued that other heat transfer processes would tend to supply heat to the radiating surfaces, e.g. by condensation, rather than to remove it by evaporation. Nevertheless, such observations as have previously been made of water-vapour fluxes after dark (e.g. by Pasquill, 1949, Rider, 1954, and SwinBANK, 1955) suggest that slight evaporation may occur after sunset in suitable 